\title{
Effect of untreated dental caries on school performance and social life
}

\author{
Ameera Ibrahim Amer ${ }^{1 *}$, Walaa Yahia Alsehaim², Wissam Hussain Alabdalaal ${ }^{3}$, \\ Ohood Mohammad Alsemran ${ }^{4}$, Osama Mohammad Mansori ${ }^{5}$, Daren Sleman Almahmadi ${ }^{6}$, \\ Mayar Saleh Subahi ${ }^{7}$, Monthir Mohammed Feteih ${ }^{8}$, Shahad Amer Alshehri', \\ Malik Farraj Alasmari ${ }^{10}$, Manar Abdullah Alqahtani ${ }^{11}$
}

\author{
${ }^{1}$ Department of Pediatric Dentistry, East Jeddah Hospital, Jeddah, Saudi Arabia \\ ${ }^{2}$ Wasat Abha Primary Healthcare Center, Ministry of Health, Abha, Saudi Arabia \\ ${ }^{3}$ Dental Department, Qatif Central Hospital, Qatif, Saudi Arabia \\ ${ }^{4}$ Taif Primary Healthcare Center, Ministry of Health, Taif, Saudi Arabia \\ ${ }^{5}$ College of Dentistry, King Abdulaziz University, Jeddah, Saudi Arabia \\ ${ }^{6}$ General Dentist, Ministry of Health, Al Qurayyat, Saudi Arabia \\ ${ }^{7}$ College of Dentistry, Umm Al-Qura University, Mecca, Saudi Arabia \\ ${ }^{8}$ Dental Department, East Jeddah Hospital, Jeddah, Saudi Arabia \\ ${ }^{9}$ General Dentist, Ministry of Health, Jeddah, Saudi Arabia \\ ${ }^{10}$ Dental Department, Prince Mohammed bin Abdulaziz Hospital, Riyadh, Saudi Arabia \\ ${ }^{11}$ College of Dentistry, King Khalid University, Abha, Saudi Arabia
}

Received: 15 November 2021

Accepted: 29 November 2021

\section{*Correspondence:}

Dr. Ameera Ibrahim Amer,

E-mail: ameera-dent@hotmail.com

Copyright: ( $)$ the author(s), publisher and licensee Medip Academy. This is an open-access article distributed under the terms of the Creative Commons Attribution Non-Commercial License, which permits unrestricted non-commercial use, distribution, and reproduction in any medium, provided the original work is properly cited.

\begin{abstract}
Oral diseases are highly prevalent across the different countries globally, indicating that these conditions represent a significant challenge to the healthcare authorities. Moreover, like untreated dental caries, chronic diseases were linked with poor school performance and deteriorated quality of life. This current literature review aims to discuss the effect of untreated dental caries on school performance and social life. Our findings indicate the strong association between having untreated dental caries and reduced performance at school. We also found that these children usually suffer from deteriorated aspects of social life, being more prone to verbal bullying than other children without dental caries. Different factors were reported to affect the correlation between untreated dental caries and performance at school. For instance, socioeconomic status has a significant role in this association. Evidence also indicates the vital role of gender, family income, and parental education. These findings indicate the urgent need to draw proper interventional plans to reduce the risk of dental caries. Besides, healthcare authorities should plan for screening programs to detect children with untreated dental caries and provide adequate management of these conditions to enhance the quality of life and educational aspects. However, the findings are not consistent among the different investigations in the literature. Therefore, future studies are needed to validate the current evidence and enhance the outcomes.
\end{abstract}

Keywords: Dental caries, Treatment, Social life, Quality of life, Oral diseases

\section{INTRODUCTION}

Oral diseases are highly prevalent across the different countries globally, indicating that these conditions represent a significant challenge to the healthcare authorities. ${ }^{1}$ However, it should be noted that dental caries prevalence rates have significantly reduced over time. ${ }^{2}$ This has been attributed to the advances in the quality of care. Besides, increased awareness among populations 
about the potential risks of these disorders contributed to the low prevalence of these conditions.

Education is essential for societal progress and human development, especially for young children. ${ }^{3}$ However, different factors were reported to affect the process of education and school performance. Some of these factors include environmental factors, improper socio-cultural surroundings, emotional difficulties, hyperactivity disorder, attention deficit, learning disabilities, cognitive impairment, and having medical problems. ${ }^{3}$ Like untreated dental caries, chronic conditions were linked with reduced performance at school and deteriorated quality of life. ${ }^{4-6}$ The present literature review hopes to properly discuss whether untreated dental caries can affect school performance and social life.

\section{METHODS}

This literature review is based on an extensive literature search in Medline, Cochrane, and EMBASE databases which was performed on 2nd October 2021 using the medical subject headings (MeSH) or a combination of all possible related terms, according to the database. To avoid missing poetential studies, a further manual search for papers was done through Google Scholar, while the reference lists of the initially included papers. Studies discussing effect of untreated dental caries on school performance and social life were screened for useful information, with no limitations posed on date, language, age of participants, or publication type.

\section{DISCUSSION}

Different studies have assessed the impact of untreated dental caries on the affected children's school performance and social life. The findings of these investigations will be discussed in the following section. Evidence shows that there are many negative impacts of dental caries on the quality of life of the affected children, especially during the early adolescence period. This has been attributed to the significant reduction of effectiveness of masticatory functions and affecting general appearance. Therefore, this can remarkably affect the growth and development of the affected children and impact their social life and related daily activities. Eid et al conducted previous crosssectional research in Egypt and included schoolchildren aged $11-14 .^{7}$ The authors demonstrated that the association between dental caries and oral health-related quality of life was significant among the included school children. Furthermore, it has been estimated that mean values of untreated caries and cavities were significantly lower among females than males. This has been attributed to the potential that girls usually take more care of their oral health, like frequently brushing their teeth, than boys. These findings were also reportedly significant with previous similar investigations in the literature. ${ }^{8,9}$ In the same context, a previous cross-sectional study by Souza et al was conducted in Brazil to assess the impact of untreated dental caries on the social parameters of 12-year old children. It has been concluded that the presence of dental caries was significantly associated with deteriorated specific daily activities, including sleep disturbances and eating patterns. Furthermore, the psychological domain of the oral health-related quality of life was also correlated with having untreated dental caries in these children. ${ }^{10}$

It should be noted that previous investigations have demonstrated that pain was the most significant symptom that has been associated with remarkably impacting daily activities of the affected children, including sleeping, peaking, and eating activities. ${ }^{11,12}$ Thus, untreated dental caries can significantly lead to a vicious cycle, as previously suggested. ${ }^{7}$ Untreated dental caries can lead to remarkable painful sensations and tooth loss. This will subsequently make it hard for these children to chew hard food. Therefore, the type of food for these children will be shifted from hard into soft and processed food to meet the poor masticatory functions of these children. This type of food is usually of low nutritional status and more cariogenic than hard food, influencing the development and progression of new dental caries, increasing soft food consumption, etc. Moreover, studies have also demonstrated that this type of food administration can significantly reduce growth and development among these children. ${ }^{13,14}$ Evidence also shows that the effect of oral symptoms secondary to untreated dental caries can also negatively impact the emotional aspects of the affected children. ${ }^{7}$ This can be attributed to the significant deterioration in the affected child's self-esteem due to the remarkable impact on sleeping, speaking, and eating activities. $^{13,15}$ It has been further demonstrated that different demographics and socioeconomic factors also play a fundamental role in developing caries and their association with the quality of life of the impacted children. For instance, evidence indicates that the mothers' educational level to the affected children and financial status play a critical role in this regard. These factors are essential in determining the lifestyle of the different habits, and the differnet preventive measures, such as taking care of oral health. Besides, low socioeconomic status can intervene against adequate access to oral healthcare services.

Another cross-sectional investigation conducted by Quadros et al also demonstrated that the presence of untreated dental caries was significantly correlated with an inverse association on school performance among children from low socioeconomic communities. ${ }^{16}$ Accordingly, it has been demonstrated that untreated dental caries can substantially predict the school performance of these children. Furthermore, more deteriorated school performance and higher frequencies of untreated dental caries were also significant among males than females in this investigation. Many previous investigations have also indicated the association between poor school performance and untreated dental caries from different countries worldwide. ${ }^{4,6,17-19}$ Although it has been evidenced that untreated dental caries can negatively impact school performance, the association between these two variables 
is not adequately understood, as most of the previously published investigations usually concentrate on having a previous experience of dental caries. ${ }^{20}$ In this context, a previous study reported that more verbal bullying was significantly associated with children that had untreated dental caries more than other disease-treated or caries-free children. Accordingly, the authors suggested that extensive dental caries could substantially impact children's socialization and interpersonal relationships. ${ }^{21}$

The related school bullying might be attributed to the potential aesthetic issues that might follow the pathophysiology of untreated dental caries. This can inversely affect school performance among children and hinder their social activities. However, it should be noted that future investigations might be needed in this context to furtherly elaborate the psychological relation between school performance and dental caries. Evidence indicates that the clinical consequences resulting from untreated dental caries are directly correlated with reduced school performance. On the other hand, an indirect association was found between poor school performance and previous dental caries experience. ${ }^{16}$ The clinical patterns of untreated dental caries, which might affect educational harvest, might include discomfort and pain. As previously mentioned, these manifestations are usually associated with issues regarding eating and chewing and sleep disturbances. This can significantly impair the child's learning abilities and concentration and impair his school performance. $^{22}$ Furthermore, having experience with dental caries can influence the academic performance of the affected children by triggering a sequel and severity of the dental condition.

The psychological and functional impairments following untreated dental caries can significantly impair the expected learning process, schoolwork, and school attendance. ${ }^{23}$ Missing school was also a potential risk factor for academic deterioration and school progress. ${ }^{5}$ This has been indicated in a previous meta-analysis, which analyzed the findings from 15 primary investigations. The authors reported that the consequences of dental caries significantly impacted the educational attainment of children. It has been further demonstrated that poor school performance was $44 \%$ higher among adolescents with $\geq$ decayed tooth. ${ }^{24}$ Another investigation in the United States also showed that having difficulties in school was significantly associated with at least one oral condition among adolescents and children. The reported conditions include gingivitis, current dental caries, and dental pain. The authors also noted that being 12-14 years old was twice more prone to have school difficulties than other included children. ${ }^{22}$

Dental caries is a chronic condition, and previous investigations have linked having poor school performance and the presence of chronic oral health-related diseases. ${ }^{25}$ On the other hand, it should also be noted that some previous studies reported that there was no association between school performance and oral health status. ${ }^{26,27}$
However, these findings might be limited to these populations, and the discrepancy in results of the different studies might be attributed to the various methodological approaches and different demographics of the included populations. Besides, using different strategies for assessing school performance can also impact the findings and cause discrepancies among the relevant investigations. For example, some studies used grading systems and specific tools for evaluating school performance, while others used self-reported questionnaires. ${ }^{24}$

The association between school performance and dental status is complex and might be attributed to several pathways and different factors. ${ }^{23}$ Among the reported factors, socioeconomic status has been a significant predictor of school performance and oral health. Accordingly, this factor should be considered among the different investigations that aim to assess the correlation between school performance and oral health. We previously mentioned that the mother's educational level and monthly income were significantly associated with predicting school performance among children with untreated dental caries. On the other hand, it has been reported that neither family income nor skin color was significantly associated with school performance. ${ }^{16}$ However, it should be noted that there is a significant discrepancy in these parameters among the different studies. For instance, some studies indicated that low socioeconomic status, low parental educational levels, and being non-white male were all significant factors associated with poor school performance. ${ }^{28-30}$ The differences between the different investigations can be attributed to the distribution of samples and their baseline characteristics. It has been furtherly demonstrated that gender can also predict the correlation between untreated dental caries and educational outcomes. ${ }^{16}$ Most studies report that boys usually have higher frequencies of dental caries, and consequently, poorer school performance. This is because boys are less likely to use dental services and take care of their oral hygiene than females. ${ }^{31}$ On the other hand, girls usually adopt enhanced preventive measures to improve their health and aesthetics. ${ }^{32}$ Moreover, enhanced academic performance among girls might be attributed to several factors, including higher academic motivation, more excellent perception of educational requirements, and greater perception of the required emotional demands from teachers. These parameters were more significant for girls than boys, partially explaining the enhanced academic performance of boys with untreated dental caries. ${ }^{33}$

Many recent investigations support the association between oral health status and different domains of healthrelated quality of life. ${ }^{34-36}$ For instance, functional oral health status has been found to correlate with untreated dental caries significantly. Thus, evidence indicates that functional oral health status is an essential domain considered when assessing health-related quality of life. ${ }^{35}$ Furthermore, routine everyday activities and reduced oral health-related quality of life were significantly correlated with having a decayed tooth. ${ }^{34-36}$ In this context, results 
from previous investigations have formulated strong evidence regarding the benefits obtained from adequately applying dental interventions in improving the quality of life of the affected children. Some of these interventions might include the treatment of malocclusion and dental caries. This furtherly indicates the association between dental caries and quality of life. ${ }^{37,38}$ These findings indicate the urgent need to draw proper interventional plans to reduce the risk of dental caries. Besides, healthcare authorities should plan for screening programs to detect children with untreated dental caries and provide adequate management of these conditions to enhance the quality of life and school performance. Finally, targeting a population that is at increased risk is a priority in this context. These populations can be identified based on the reported correlated demographics and socioeconomic factors significantly.

\section{CONCLUSION}

Children usually suffer from deteriorated aspects of social life, being more prone to verbal bullying than other children without dental caries. Different factors were reported to affect the correlation between untreated school performance and dental caries. For instance, socioeconomic status has a significant role in this association. Evidence also indicates the vital role of gender, family income, and parental education. However, the findings are not consistent among the different investigations in the literature. Therefore, future studies are needed to validate the current evidence and enhance the outcomes.

\section{Funding: No funding sources \\ Conflict of interest: None declared \\ Ethical approval: Not required}

\section{REFERENCES}

1. Kassebaum NJ, Smith AGC, Bernabé E. Global, Regional, and National Prevalence, Incidence, and Disability-Adjusted Life Years for Oral Conditions for 195 Countries, 1990-2015: A Systematic Analysis for the Global Burden of Diseases, Injuries, and Risk Factors. Journal of dental research. 2017;96(4):380-7.

2. Peres MA, Macpherson LMD, Weyant RJ. Oral diseases: a global public health challenge. Lancet. 2019;394(10194):249-60.

3. Karande S, Kulkarni M. Poor school performance. Indian journal of pediatrics. 2005;72(11):961-7.

4. Jackson SL, Vann WF, Jr., Kotch JB, Pahel BT, Lee JY. Impact of poor oral health on children's school attendance and performance. American journal of public health. 2011;101(10):1900-6.

5. Ruff RR, Senthi S, Susser SR, Tsutsui A. Oral health, academic performance, and school absenteeism in children and adolescents: A systematic review and meta-analysis. Journal of the American Dental Association (1939). 2019;150(2):111-21.
6. Seirawan H, Faust S, Mulligan R. The impact of oral health on the academic performance of disadvantaged children. American journal of public health. 2012;102(9):1729-34.

7. Eid SA, Khattab NMA, Elheeny AAH. Untreated dental caries prevalence and impact on the quality of life among 11 to14-year-old Egyptian schoolchildren: a cross-sectional study. BMC oral health. 2020;20(1):83.

8. Abbass MMS, Mahmoud SA, El Moshy S. The prevalence of dental caries among Egyptian children and adolescences and its association with age, socioeconomic status, dietary habits and other risk factors. A cross-sectional study. F1000Res. 2019;8:8.

9. Mamai-Homata E, Koletsi-Kounari H, Margaritis V. Gender differences in oral health status and behavior of Greek dental students: A meta-analysis of 1981, 2000, and 2010 data. Journal of International Society of Preventive \& Community Dentistry. 2016;6(1):60-8.

10. Souza J, Souza S, Noronha M, Ferreira E, Martins A. Impact of untreated dental caries on the daily activities of children: Impact of untreated dental caries. Journal of public health dentistry. 2017;78.

11. Jürgensen N, Petersen PE. Oral health and the impact of socio-behavioural factors in a cross sectional survey of 12-year old school children in Laos. BMC oral health. 2009;9:29.

12. Bastos RS, Carvalho ES, Xavier A, Caldana ML, Bastos JR, Lauris JR. Dental caries related to quality of life in two Brazilian adolescent groups: a crosssectional randomised study. International dental journal. 2012;62(3):137-43.

13. Gilchrist F, Marshman Z, Deery C, Rodd HD. The impact of dental caries on children and young people: what they have to say? International journal of paediatric dentistry. 2015;25(5):327-38.

14. Lima SLA, Santana CCP, Paschoal MAB, Paiva SM, Ferreira MC. Impact of untreated dental caries on the quality of life of Brazilian children: population-based study. International journal of paediatric dentistry. 2018;28(4):390-9.

15. Kaur P, Singh S, Mathur A. Impact of Dental Disorders and its Influence on Self Esteem Levels among Adolescents. Journal of clinical and diagnostic research: JCDR. 2017;11(4):Zc05-zc08.

16. Quadros LN, Rebelo MAB, de Queiroz AC, Pereira JV, Vettore MV, Rebelo Vieira JM. Clinical consequences of untreated dental caries and school performance in low-income adolescents. International journal of paediatric dentistry. 2021;31(5):619-26.

17. de Paula JS, Ambrosano GM, Mialhe FL. Oral Disorders, Socioenvironmental Factors and Subjective Perception Impact on Children's School Performance. Oral health \& preventive dentistry. 2015;13(3):219-26.

18. El-Sayed M, Osman K, Nour A. Prevalence of dental caries and its impact on the academic performance of Sudanese basic school children, Al-Sahafa residential 
area (2013-2014). The Journal of American Science. 2015;11(4):195-203.

19. Paula JS, Lisboa CM, Meneghim Mde C, Pereira AC, Ambrosano GM, Mialhe FL. School performance and oral health conditions: analysis of the impact mediated by socio-economic factors. International journal of paediatric dentistry. 2016;26(1):52-9.

20. Karki S, Päkkilä J, Laitala ML, Humagain M, Anttonen V. Influence of dental caries on oral healthrelated quality of life, school absenteeism and school performance among Nepalese schoolchildren. Community dentistry and oral epidemiology. 2019;47(6):461-9.

21. Barasuol JC, Soares JP, Castro RG. Untreated Dental Caries Is Associated with Reports of Verbal Bullying in Children 8-10 Years Old. Caries research. 2017;51(5):482-8.

22. Guarnizo-Herreño CC, Lyu W, Wehby GL. Children's Oral Health and Academic Performance: Evidence of a Persisting Relationship Over the Last Decade in the United States. The Journal of pediatrics. 2019;209:183-9.

23. Krisdapong S, Prasertsom P, Rattanarangsima K, Sheiham A. School absence due to toothache associated with sociodemographic factors, dental caries status, and oral health-related quality of life in 12- and 15-year-old Thai children. Journal of public health dentistry. 2013;73(4):321-8.

24. Rebelo MAB, Rebelo Vieira JM, Pereira JV, Quadros LN, Vettore MV. Does oral health influence school performance and school attendance? A systematic review and meta-analysis. International journal of paediatric dentistry. 2019;29(2):138-48.

25. Hoffmann I, Diefenbach C, Gräf C. Chronic health conditions and school performance in first graders: A prospective cohort study. PloS one. 2018;13(3):e0194846.

26. Almeida RF, Leal SC, Medonca JGA, Hilgert LA, Ribeiro APD. Oral health and school performance in a group of schoolchildren from the Federal District, Brazil. Journal of public health dentistry. 2018;78(4):306-12.

27. Piovesan C, Antunes JL, Mendes FM, Guedes RS, Ardenghi TM. Influence of children's oral healthrelated quality of life on school performance and school absenteeism. Journal of public health dentistry. 2012;72(2):156-63.

28. Kaewkamnerdpong I, Krisdapong S. Oral diseases associated with condition-specific oral health-related quality of life and school performance of Thai primary school children: A hierarchical approach. Community dentistry and oral epidemiology. 2018;46(3):270-9.
29. Blumenshine SL, Vann WF, Jr., Gizlice Z, Lee JY. Children's school performance: impact of general and oral health. Journal of public health dentistry. 2008;68(2):82-7.

30. Oliva MIG, Cunha IPD, Silva AND. Sense of coherence and factors associated with school performance of adolescents. Ciencia \& saude coletiva. 2019;24(8):3057-66.

31. Maffioletti F, Vettore MV, Rebelo M. Predisposing, enabling, and need characteristics of dental services utilization among socially deprived schoolchildren. Journal of public health dentistry. 2020;80(2):97-106.

32. Baiju RM, Peter E, Narayan V, Varughese JM, Varghese NO. Do Children of Working Mothers Experience More Dental Caries? Contemporary clinical dentistry. 2018;9(4):541-7.

33. Låftman BS, Modin B. School-performance indicators and subjective health complaints: are there gender differences? Sociology of health \& illness. 2012;34(4):608-25.

34. Alwadi MAM, Vettore MV. Are school and home environmental characteristics associated with oral health-related quality of life in Brazilian adolescents and young adults? Community dentistry and oral epidemiology. 2017;45(4):356-64.

35. Baker SR, Mat A, Robinson PG. What psychosocial factors influence adolescents' oral health? Journal of dental research. 2010;89(11):1230-5.

36. Gururatana O, Baker SR, Robinson PG. Determinants of children's oral-health-related quality of life over time. Community dentistry and oral epidemiology. 2014;42(3):206-15.

37. Antunes L, Andrade M, Leão A, Maia L, Luiz R. Change in the Quality of Life of Children and Adolescents Younger than 14 Years Old after Oral Health Interventions: A Systematic Review. Pediatric dentistry. 2013;35:37-42.

38. de Paula JS, Sarracini KL, Meneghim MC. Longitudinal evaluation of the impact of dental caries treatment on oral health-related quality of life among schoolchildren. European journal of oral sciences. 2015;123(3):173-8.

Cite this article as: Amer AI, Alsehaim WY, Alabdalaal WH, Alsemran OM, Mansori OM, Almahmadi DS, et al. Effect of untreated dental caries on school performance and social life. Int $\mathbf{J}$ Community Med Public Health 2022;9:481-5. 